\title{
Accuracy of estimates of food portion size using food photographs - the importance of using age-appropriate tools
}

\author{
Emma Foster ${ }^{1, *}$, John NS Matthews ${ }^{2}$, Michael Nelson ${ }^{3}$, Julie M Harris ${ }^{4}$, \\ John $C$ Mathers $^{1}$ and Ashley J Adamson ${ }^{1}$ \\ 'Human Nutrition Research Centre, University of Newcastle upon Tyne, William Leech Building, Medical School, \\ Framlington Place, Newcastle upon Tyne NE2 4HH, UK: ${ }^{2}$ School of Mathematics and Statistics, University of \\ Newcastle upon Tyne, Newcastle upon Tyne, UK: ${ }^{3}$ Department of Nutrition and Dietetics, King's College London, \\ London, UK: ${ }^{4}$ School of Psychology, University of St Andrews, St Andrews, UK
}

Submitted 14 March 2005: Accepted 31 August 2005

\begin{abstract}
Background: In order to obtain a measure of nutrient intake, a measure or estimate of the amount of food consumed is required. Weighing foods imposes a large burden on subjects, often resulting in underreporting. Tools are available to assist subjects in providing an estimate of portion size and these include food photographs. The application of these tools in improving portion size estimation by children has not been investigated systematically.

Objectives: To assess the accuracy with which children are able to estimate food portion sizes using food photographs designed for use with adults, and to determine whether the accuracy of estimates is improved when age-appropriate portion size photographs are provided.

Design: Original data from three separate studies, on the accuracy of portion size estimates by adults using food photographs, by children using adult photographs and by children using age-appropriate photographs, are analysed and compared.

Subjects: One hundred and thirty-five adults aged 18 to 90 years and 210 children aged 4 to 11 years.

Results: Children's estimates of portion sizes using age-appropriate food photographs were significantly more accurate (an underestimate of $1 \%$ on average) than estimates using photographs designed for use with adults (an overestimate of $45 \%$ on average). Accuracy of children's estimates of portion size using age-appropriate photographs was not significantly different from that of adults. Children overestimated a food's weight by $18 \%$ on average and adults underestimated by $5 \%$.

Conclusions: Providing children with food photographs depicting age-appropriate portion sizes greatly increases the accuracy of portion size estimates compared with estimates using photographs designed for use with adults.
\end{abstract}

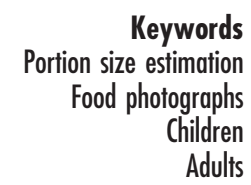

There is increasing evidence that the quality of food intake during childhood is important for health in adult life $\mathrm{e}^{1,2}$ and that eating habits formed early in life may be retained into adulthood $^{3,4}$. The proven link between diet and risk of disease, along with the importance of diet during childhood for heath in adult life, requires that children's diets be measured accurately. To monitor the diets of populations there is a need for methods which are accurate, easy to use and appropriate to the target population. Estimating the dietary intake of young children presents unique difficulties.

For intakes of food to be converted into nutrient intakes, a measure or estimate of the amount of each food consumed is required. Alternatives to weighed intakes are desirable as the task of weighing foods increases the burden placed on the subject, and the more burdensome the method the more likely it will be to result in changes to dietary intake and inaccurate reports ${ }^{5}$. Where children are the subjects of dietary investigations, weighing foods consumed outside the home and away from the parents poses additional practical problems.

As an alternative to weighing all foods, average portion sizes across the population may be used. For adults average portion sizes for some foods are available ${ }^{6}$, but no equivalent data exist for children. Work towards the publication of average portion sizes for children based on the National Diet and Nutrition Survey ${ }^{7}$ has been completed recently at the University of Dundee . $^{8}$

Assuming an average portion size for all subjects participating in a study may be appropriate in some cases, but many studies require a more precise estimate of the portion size consumed by each individual. A number of 
methods of measuring dietary intake rely on subjects' estimates of portion size. Tools are available to assist the subject with doing this such as food photographs, food replicas and food models ${ }^{9-11}$. Evidence from work with adults suggests that food photographs may improve portion size estimation compared with unaided estimates ${ }^{12}$, but there has been limited research into the accuracy with which children can use portion size assessment aids. Frobisher and Maxwell compared children's ability to estimate food portion sizes with that of adults ${ }^{13}$. The 37 children taking part in the study ranged in age from 6 to 16 years (mean age: 12 years 2 months). The subjects were asked to serve themselves with their usual portion size of nine food items which were taken away and weighed. The subjects were then asked to give a verbal description of the portion size of each food (small, medium or large) and were asked to identify the portion size of the food using the photographic atlas of food portion size designed for use by adults?. The authors found, as might be expected, that there were greater errors with children estimating portion sizes using both descriptions and food photographs compared with adults $^{13}$. In addition, there was also a tendency for food portion sizes to be overestimated by both adults and children.

Livingstone and Robson commented that the assumption that including an aid to estimating portion size will increase the accuracy of children's dietary reports has not been verified as yet ${ }^{14}$. Food photographs designed and validated for use with adults have been used quite widely as a visual aid to portion size assessment with children $^{15-17}$ despite there being little or no knowledge of the photographs' validity for use with subjects under 16 years of age.

The aims of the present project were to assess the accuracy with which children are able to estimate food portion sizes using food photographs designed for use with adults, to determine whether the accuracy of estimates is improved when age-appropriate portion size photographs are provided, and to compare children's ability to estimate portion size using the two methods with that of adults.

\section{Method}

The data presented were collected during three separate studies which examined the accuracy of:

1. Adults' estimates of food portion sizes using food photographs designed for use with adults ${ }^{12}$ (study $\mathrm{A}^{\mathrm{a}}$ ).

2. Children's estimates of food portion sizes using the food photographs designed for use with adults ${ }^{18}$ (study $\mathrm{C}^{\mathrm{a}}$ ).

3. Children's estimates of food portion sizes using food photographs developed for use with children and based on age-appropriate portion sizes ${ }^{19}$ (study $\mathrm{C}^{\mathrm{C}}$ ).
Adult estimates using food photographs $\left(A^{a}\right)$.

Full details of the methods used in this study assessing the ability of adults to estimate food portion sizes using food photographs are given elsewhere ${ }^{12}$. In brief, 135 adults (aged 18-90 years) were invited to serve themselves with a number of foods in preparation for eating them. The foods $(n=22)$ were chosen to be foods which were commonly consumed and to represent a range of morphologies. Details of the foods included are given in Table 1 . The foods were weighed by investigators at the time of serving and any leftovers were also weighed. Subjects were interviewed within 5 min of completing their meal and asked to indicate, using food photographs ${ }^{9}$, the amount of food they had consumed.

Child estimates using adult photographs $\left(C^{a}\right)$

For this study, children (aged 4-11 years) were shown plates containing foods of known weights. The foods $(n=16)$ were foods commonly consumed by children taking part in a fruit and vegetable intervention study ${ }^{16}$ and were chosen to represent a range of morphologies (Table 1). The children were asked to estimate the amount of food on the plate, using food photographs designed for use with adults 9 . Two test situations were used, with each child completing both test situations; estimates were made by the children either with the food in front of them or $24 \mathrm{~h}$ after having been shown the food. Half of the children completed the '24-hour recall' interview first and half completed the 'food in front' interview first.

Table 1 Details of the foods included in each study

\begin{tabular}{|c|c|c|}
\hline $\begin{array}{l}\text { Adults with adult } \\
\text { photos }\left(A^{a}\right)\end{array}$ & $\begin{array}{l}\text { Children with } \\
\text { adult photos }\left(C^{a}\right)\end{array}$ & $\begin{array}{l}\text { Children with } \\
\text { age-specific photos }\left(C^{c}\right)\end{array}$ \\
\hline $\begin{array}{l}\text { Boiled potato } \\
\text { Bolognese sauce } \\
\text { Broccoli } \\
\text { Cabbage } \\
\text { Cheese (grated) } \\
\text { Peas } \\
\text { Quiche } \\
\text { Rice } \\
\text { Rice pudding } \\
\text { Shepherd's pie } \\
\text { Spaghetti } \\
\text { Steak }\end{array}$ & $\begin{array}{l}\text { Apple } \\
\text { Bread } \\
\text { Milk } \\
\text { Orange squash } \\
\text { Sausages } \\
\text { Tomato ketchup } \\
\text { Banana } \\
\text { Macaroni cheese } \\
\text { Rice krispies }\end{array}$ & $\begin{array}{l}\text { Margarine } \\
\text { Cornflakes } \\
\text { Stew } \\
\text { Apple } \\
\text { Bread } \\
\text { Milk } \\
\text { Orange squash } \\
\text { Sausages } \\
\text { Tomato ketchup } \\
\text { Biscuit (Rocky) } \\
\text { Crisps } \\
\text { Custard } \\
\text { Golden syrup } \\
\text { Mixed vegetables } \\
\text { Porridge } \\
\text { Raisins } \\
\text { Sugar } \\
\text { Tea }\end{array}$ \\
\hline
\end{tabular}


Child estimates using age-specific food photographs $\left(C^{c}\right)$ For this study children were served with foods of known weights to consume. Any food left uneaten was weighed. The children were asked to estimate the amount of food they were served and, if appropriate, their leftovers. The foods included in the study $(n=23)$ were foods commonly consumed by a national sample of children ${ }^{7}$, chosen to represent a range of morphologies (Table 1). Estimates were made by children with the food in front of them, just after having eaten the food or $24 \mathrm{~h}$ after having eaten the food. Portion sizes were estimated using food photographs designed for use with children and based on children's portion sizes ${ }^{7}$. Four sets of food photographs were produced based on portion sizes appropriate to each of four age groups (4- to 6-year-olds, 7- to 10-year-olds, 11- to 14-year-olds and 15- to 16-year-olds). Seven images depicting weights from the 5 th to the 95 th centile of weight served were presented for estimation of the amount of food served. We also included seven weights down from the 5 th centile to the smallest presentable portion to enable us to obtain a measure of the amount of food left over. The portion sizes of foods served to the children were either the 25 th, 50 th or 75 th centile of the amount of food consumed for that individual food ${ }^{7}$. The weight of food presented to the child did not exactly match the weight depicted in the food photographs and children were instructed that they could indicate that the portion size was in between two photographs if they wished.

The designs of each of the studies were slightly different as were the foods included in the studies. A summary of the studies is given in Table 2.

\section{Statistical analysis}

The data were analysed in three ways:

1. Including all data from all studies (all foods and all test types).

2. Including all test types but only for foods which were common to all three studies.

3. Including only foods which were common to all three studies and comparing similar interview types, e.g.
Food in front (FIF) - child estimates using adult photos versus child estimates using age-appropriate photos;

Just after eating (JAE) - adult estimates using adult photos versus child estimates using age-appropriate photos.

Analysis was performed on the ratio of the subject's estimate to the actual weight of the food. A value greater than 1 indicated overreporting and a value less than 1 indicated underreporting.

The accuracy of the portion size estimates was assessed by plotting the geometric mean of the ratio of the estimate of the amount of food served (or consumed) against the actual weight of the food served (or consumed). Error bars, depicting the mean $\pm 2 \mathrm{SD}$ (standard deviations), gave an estimate of the precision of the measurement.

To compare the relative performance of the adults using adult portion size photographs, children using the adult photographs and children using the age-appropriate portion size photographs, a univariate analysis of variance with child ID and study as fixed factors was performed.

\section{Results}

The age and gender of subjects participating in each of the three studies are given in Table 2. All three studies included a large number of people for this type of study (study $\mathrm{A}^{\mathrm{a}}, n=135$; study $\mathrm{C}^{\mathrm{a}}, n=55$; study $\mathrm{C}^{\mathrm{C}}, n=155$ ) and a proportionate balance of males to females. Table 3 shows that when all data from all studies were included (all foods and all test types) there were significant differences between the three studies in the accuracy of estimates of portion size. Adults overestimated portion size by $18 \%$ on average. Children overestimated portion size by $46 \%$ on average using food photographs designed for use with adults; however, when using age-appropriate photographs the children were on average more accurate than adults in their estimates of portion size, overestimating by $7 \%$ (Table 3 ).

When only the foods which featured in all three studies were included in the analysis, there were significant

Table 2 Summary of details of each study included in the present paper

\begin{tabular}{|c|c|c|c|c|c|c|c|}
\hline Study & $\begin{array}{l}\text { Food } \\
\text { eaten }\end{array}$ & Estimated & Test situations & $\begin{array}{l}\text { No. of } \\
\text { subjects }\end{array}$ & $\begin{array}{l}\text { Age (years), } \\
\text { mean (range) }\end{array}$ & $\begin{array}{l}\text { Males/ } \\
\text { females }\end{array}$ & Reference \\
\hline $\begin{array}{l}\text { Adults with adult } \\
\text { photos }\left(A^{a}\right)\end{array}$ & Yes & $\begin{array}{l}\text { Amount of food } \\
\text { eaten }\end{array}$ & Just after eating & 135 & $42.7(18-90)$ & $74 / 61$ & 12 \\
\hline $\begin{array}{l}\text { Children with adult } \\
\text { photos }\left(C^{a}\right)\end{array}$ & No & $\begin{array}{l}\text { Amount of food } \\
\text { served }\end{array}$ & $\begin{array}{l}\text { Food in front } \\
24-\text { Hour recall }\end{array}$ & 55 & $9.5(4-11)$ & $25 / 30$ & 18 \\
\hline $\begin{array}{l}\text { Children with } \\
\text { age-specific } \\
\text { photos }\left(\mathrm{C}^{\mathrm{C}}\right)\end{array}$ & Yes & $\begin{array}{l}\text { Amount of food } \\
\text { served and if } \\
\text { appropriate amount } \\
\text { leftover }\end{array}$ & $\begin{array}{l}\text { Food in front } \\
\text { Just after eating } \\
24-\text { Hour recall }\end{array}$ & 155 & $7.9(4-11)$ & $78 / 77$ & 19 \\
\hline
\end{tabular}


Table 3 Accuracy of estimates of portion size - including all foods and all test types

\begin{tabular}{|c|c|c|c|c|c|}
\hline \multirow[b]{2}{*}{ Study } & \multirow[b]{2}{*}{ No. of estimates } & \multirow[b]{2}{*}{ Mean ratio* } & \multicolumn{2}{|c|}{$\begin{array}{c}95 \% \\
\text { Confidence } \\
\text { interval }\end{array}$} & \multirow[b]{2}{*}{$P$-value } \\
\hline & & & Lower & Upper & \\
\hline$A^{a}$ & 590 & 1.18 & 1.120 & 1.238 & $<0.001$ \\
\hline $\mathrm{C}^{\mathrm{a}}$ & 1744 & 1.46 & 1.392 & 1.532 & \\
\hline $\mathrm{C}^{\mathrm{C}}$ & 2855 & 1.07 & 1.037 & 1.105 & \\
\hline
\end{tabular}

$A^{a}$ - Adults' estimates of food portion sizes using food photographs designed for use with adults; $C^{a}$ - children's estimates of food portion sizes using the food photographs designed for use with adults; $\mathrm{C}^{\mathrm{C}}-$ children's estimates of food portion sizes using food photographs developed for use with children and based on age-specific portion sizes.

${ }^{*}$ A value greater than 1 indicates overreporting and a value less than 1 underreporting.

$\dagger P$-value indicates the significance of the difference between the study groups of the mean ratio of estimated food weight to actual food weight.

differences between the three studies in the accuracy of portion size estimates. Adults' estimates were most accurate, with an underestimate of $9 \%$ on average. Children using the adult photographs overestimated portion sizes by $47 \%$ on average, but when provided with age-appropriate photographs this overestimate was reduced to $28 \%$ (Table 4 ).

Figure 1 illustrates the accuracy and precision (as indicated by the error bars, which show the mean $\pm 2 \mathrm{SD}$ ) of estimates of portion size by type of food. With the exception of cheese, providing children with age-appropriate photographs resulted in more accurate estimates of portion size. The adults (in study $\mathrm{A}^{\mathrm{a}}$ ) served themselves with cheese while the children taking part in study $\mathrm{C}^{\mathrm{a}}$ were shown slices of cheese and for study $\mathrm{C}^{\mathrm{C}}$ the children were given a cheese sandwich in which the cheese was hidden from direct observation. The very different presentation of the cheese could explain this lack of precision. For baked beans $(P=0.036)$ and chips $(P=0.328)$ the children provided more accurate estimates of portion size using age-appropriate portion size

Table 4 Accuracy of estimates of portion size - including only foods common to all three studies and all test types

\begin{tabular}{|c|c|c|c|c|c|}
\hline \multirow[b]{2}{*}{ Study } & \multirow[b]{2}{*}{ No. of estimates } & \multirow[b]{2}{*}{ Mean ratio* } & \multicolumn{2}{|c|}{$\begin{array}{c}95 \% \\
\text { Confidence } \\
\text { interval }\end{array}$} & \multirow[b]{2}{*}{$P$-value } \\
\hline & & & Lower & Upper & \\
\hline$A^{a}$ & 108 & 0.91 & 0.823 & 0.996 & $<0.001$ \\
\hline $\mathrm{C}^{\mathrm{a}}$ & 545 & 1.47 & 1.408 & 1.533 & \\
\hline$C^{c}$ & 418 & 1.28 & 1.216 & 1.340 & \\
\hline
\end{tabular}

$A^{a}$ - Adults' estimates of food portion sizes using food photographs designed for use with adults; $C^{a}$ - children's estimates of food portion sizes using the food photographs designed for use with adults; $\mathrm{C}^{\mathrm{C}}-$ children's estimates of food portion sizes using food photographs developed for use with children and based on age-specific portion sizes.

* $A$ value greater than 1 indicates overreporting and a value less than 1 underreporting.

† $P$-value indicates the significance of the difference between the study groups of the mean ratio of estimated food weight to actual food weight. photographs than adults using adult portion size photographs.

When estimates for the same foods and the same interview types only were compared, no significant difference was found between adults' ability to estimate portion size just after eating the food and children's ability when the children were provided with age-appropriate tools (Table 5). Adults underestimated portion size by $5 \%$ on average whereas children were less accurate, overestimating by $18 \%$ on average. This difference was not found to be significant $(P=0.182)$. The difference between the children's ability to estimate portion size using adult photographs and estimates using age-appropriate photographs when the food was in front of them was significantly different $(P=0.001)$. Children's estimates using the age-appropriate photographs were more accurate than when using the photographs designed for adults, an underestimate of $1 \%$ on average compared with an overestimate of $45 \%$ using the adult photographs, for the same foods and under the same test conditions.

Children using the child photographs were only slightly less accurate and less precise than adults (study $\mathrm{C}^{\mathrm{C}}$ vs. study $\mathrm{A}^{\mathrm{a}}$ ) and were significantly more accurate than children using the adult photographs (study $\mathrm{C}^{\mathrm{C}}$ vs. study $\mathrm{C}^{\mathrm{a}}$ ). With the exception of estimates of the portion size of cheese, precision and accuracy of estimates were comparable with those of adults and much better than when children used the adult photographs.

\section{Discussion}

Methods of assessing dietary intake designed for use with adults are often used to measure children's diets on the assumption that validity in one population implies validity in another. To improve the accuracy of quantitative data collected on children's diets it is imperative that an alternative to weighing foods is found which is appropriate for this age group. Such an alternative method should provide an accurate assessment of the portion size of foods consumed but be easy for subjects to use and cause minimum disruption of the habitual dietary behaviour of the child. Although alternatives to weighed intakes such as food photographs ${ }^{9}$ and household measures are available, their validity for use with children has not been assessed previously.

Despite the use of slightly different designs in the studies reported in this paper, a consistent pattern of results emerged. Children using age-appropriate photographs produced estimates of portion size which were only slightly less accurate than those produced by adults (using photographs designed for adults) and more accurate than when the children were using adult food photographs.

Precision of the estimates of portion size by both adults and children in these studies was moderate, indicating that 


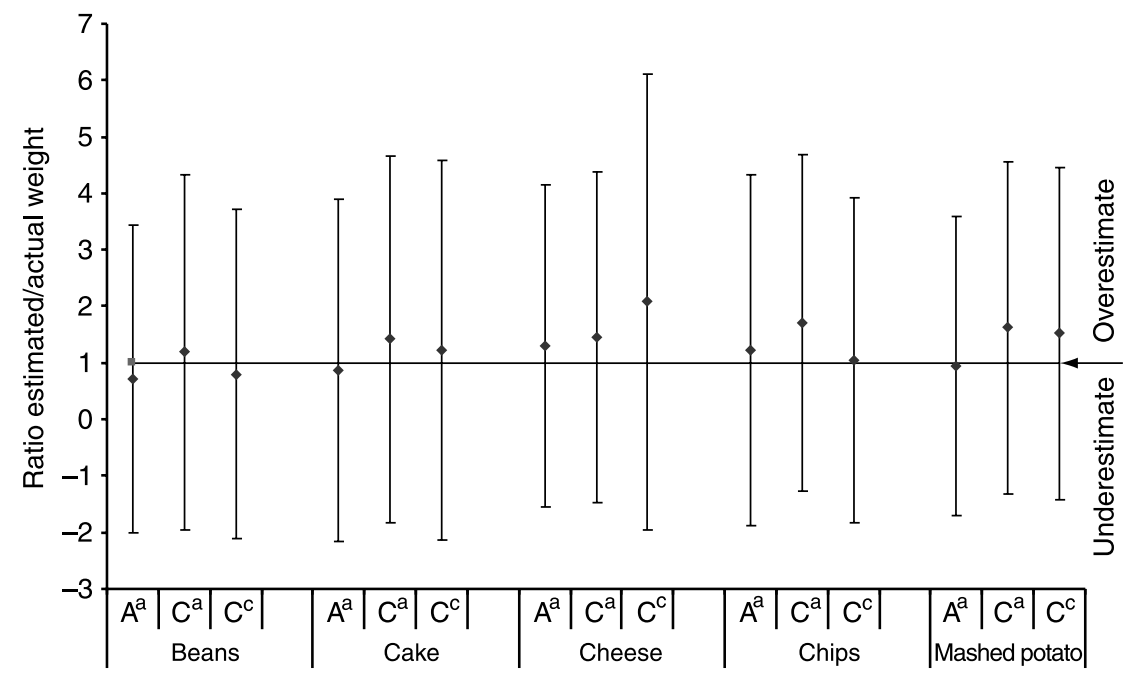

Fig. 1 Accuracy and precision of portion size estimates for individual foods - all interview types. $A^{a}-$ Adults' estimates of food portion sizes using food photographs designed for use with adults; $C^{a}$ - children's estimates of food portion sizes using the food photographs designed for use with adults; $C^{C}$ - children's estimates of food portion sizes using food photographs developed for use with children and based on age-specific portion sizes. Accuracy is defined as the proximity of the mean estimate of portion size to the actual weight of the food. Precision is defined as the range of estimates around the mean and is presented by error bars which depict the mean \pm 2 SD (standard deviations). A value greater than 1 indicates overreporting and a value less than 1 underreporting

food photographs are more suited to use in estimation of group means. Poor precision even where accuracy is high will result in a good estimate of mean intake but reduced ability either to rank individuals according to consumption or to identify extreme consumers or extreme levels of consumption.

Comparison with previous studies examining subjects' ability to estimate portion size is hampered by a lack of consistency in the way in which data are presented and the different foods included in each study. Children's estimates of mashed potato portions using the age-appropriate photographs were poor compared with earlier studies conducted in adults (an error of 52\%

Table 5 Accuracy of estimates of portion size - including only foods common to all three studies and estimates made during the same interview type

\begin{tabular}{lccccc}
\hline & & \multicolumn{4}{c}{$\begin{array}{c}95 \% \\
\text { Confidence } \\
\text { interval }\end{array}$} \\
\cline { 3 - 5 } Study & No. of estimates & Mean ratio* & Lower & Upper & $P$-value† \\
\hline $\mathrm{A}^{\mathrm{a}} \mathrm{JAE}$ & 76 & 0.95 & 0.823 & 1.106 & 0.182 \\
$\mathrm{C}^{\mathrm{C}} \mathrm{JAE}$ & 59 & 1.18 & 0.936 & 1.501 & \\
$\mathrm{C}^{\mathrm{c}} \mathrm{FIF}$ & 102 & 0.99 & 0.849 & 1.152 & 0.001 \\
$\mathrm{C}^{\mathrm{a}} \mathrm{FIF}$ & 168 & 1.45 & 1.315 & 1.607 & \\
\hline
\end{tabular}

$A^{a}$ - Adults' estimates of food portion sizes using food photographs designed for use with adults; $C^{a}$ - children's estimates of food portion sizes using the food photographs designed for use with adults; $C^{c}-$ children's estimates of food portion sizes using food photographs developed for use with children and based on age-specific portion sizes; JAE - subject was interviewed just after having eaten the food; FIF - subject was interviewed with the food in front of them.

${ }^{*} A$ value greater than 1 indicates overreporting and a value less than 1 underreporting.

$\dagger P$-value indicates the significance of the difference between the study groups of the mean ratio of estimated food weight to actual food weight. compared with $-0.9 \%$ to $7.7 \%$ reported in three studies with adults ${ }^{20-22}$ ). Compared with previously published data on children's ability to estimate portion size using adult food photographs ${ }^{13}$, children in this study using age-appropriate photographs were more accurate in their estimates of chips (median error of $-11 \%$ compared with $79 \%$ ) and mashed potato (median error of $37 \%$ compared with 56\%). Estimates of baked beans (median error of $-28.7 \%$ compared with 16\%) and cheese (median error of $132 \%$ compared with 64\%) portions were less accurate than those of children using the adult photographs. The large error associated with assessing the portion size of cheese by the children in this present study can be explained by the fact that the cheese was served as a sandwich and therefore not clearly seen by the children.

Data from the largest study of adults' portion size estimation using food photographs were combined with the data on children's estimates using both adult photographs and age-appropriate photographs to overcome this lack of consistency in presentation of data across studies. This meant that the data could be analysed in the same way. Under the same test conditions and for the same foods, children's estimates using portion size photographs based on children's portion sizes were not statistically significantly different from those of adults, but significantly more accurate than estimates made by children using the adult photographs. This highlights the need for the portion sizes presented in a photographic atlas of food to be appropriate to the target population.

The three studies reported in this paper tested the application of food photographs in an artificial situation where researchers provided and weighed all foods. The food photographs designed for use with children in this 
study were developed for pilot testing only, and so covered only a limited range of foods. This tool would need to be expanded to cover a wider range of foods and then validated against total dietary intakes in a 'real-life' situation before wider application can be recommended.

This study has demonstrated that, given age-appropriate food photographs, portion size estimation is a task even children of primary school age are able to perform with acceptable accuracy and precision. We have demonstrated that age-appropriate food photographs have potential for improving the quality of dietary intake data collected from children.

\section{Acknowledgements}

The work to develop the age-appropriate portion size assessment tools for use with children was funded by the Food Standards Agency (project number N08019). The work on adult estimates of portion size was funded by the Ministry of Agriculture, Fisheries and Food.

The authors thank the schools, teachers, children and parents who took part in this study.

\section{References}

1 Berenson GS, Srinivasan SR, Bao W, Newman WP 3rd, Tracy RE, Wattigney WA. Association between multiple cardiovascular risk factors and atherosclerosis in children and young adults. New England Journal of Medicine 1998. 338: $1650-6$.

2 Gaziano JM. When should heart disease prevention begin? New England Journal of Medicine 1998; 338: 1690-2.

3 Wardle J. Parental influences on children's diets. Proceedings of the Nutrition Society 1995; 54: 747-58.

4 Welten DC, Kemper HC, Post GB, Van Staveren WA, Twisk JW. Longitudinal development and tracking of calcium and dairy intake from teenager to adult. European Journal of Clinical Nutrition 1997; 51: 612-8.

5 Macdiarmid JI, Blundell JE. Dietary underreporting: what people say about recording their food intake. European Journal of Clinical Nutrition 1997; 51: 199-200.

6 Crawley H. Food Portion Sizes, 2nd ed. London: HMSO, 1993.

7 Gregory J, Lowe S. National Diet and Nutrition Survey: Young People aged 4 to 18 years. London: HMSO, 2000.
8 Barton KL, Wrieden WL, Longbottom PJ, Adamson AJ, Ogston SA. How accurate are standard children's food portion sizes for estimation of dietary intakes of children of different ages? Proceedings of the Nutrition Society 2003; 62 : $85 \mathrm{~A}$.

9 Nelson M, Atkinson M, Meyer J. A Photographic Atlas of Food Portion Sizes. London: MAFF Publications, 1997.

10 Hackett AF, Rugg-Gunn AJ, Appleton DR, Allinson M, Eastoe JE. Sugars-eating habits of 40511 - to 14-year-old English children. British Journal of Nutrition 1984; 51: 347-56.

11 Cameron ME, Van Staveren WA, eds. Manual on Methodology for Food Consumption Studies. Oxford: Oxford University Press, 1998.

12 Nelson M, Atkinson M, Darbyshire S. Food photography II: use of food photographs for estimating portion size and the nutrient content of meals. British Journal of Nutrition 1996; 76: $31-49$.

13 Frobisher C, Maxwell SM. The estimation of food portion sizes: a comparison between using descriptions of portion sizes and a photographic food atlas by children and adults. Journal of Human Nutrition and Dietetics 2003; 16: 181-8.

14 Livingstone MBE, Robson PJ. Measurement of dietary intake in children. Proceedings of the Nutrition Society 2000; 59: 279-93.

15 Revill SA, Adamson AJ, Stacy R, Hooper J, Moynihan P. The effect of an after school 'food club' on intake of foods and nutrients by children from deprived social backgrounds. Proceedings of the Nutrition Society 2001; 60: 189A.

16 Anderson AS, Porteous LEG, Foster E, Higgins C, Stead M, Hetherington $\mathrm{M}$, et al. The impact of a school-based nutrition education intervention on dietary intake and cognitive and attitudinal variables relating to fruits and vegetables. Public Health Nutrition 2005; 8: 650-6.

17 Curtis PJ, Adamson AJ, Mathers JC. Associations between fruit and vegetable, starch and fat consumption? Proceedings of the Nutrition Society 2001; 60: 183A.

18 Foster E. Assessing dietary intake in primary school children. $\mathrm{PhD}$ thesis, University of Newcastle upon Tyne, Newcastle upon Tyne, UK, 2003.

19 Foster E, Matthews JNS, Adamson AJ. The development and evaluation of portion size assessment tools for use with children. Proceedings of the Nutrition Society 2006; in press.

20 Nelson M, Atkinson M, Darbyshire S. Food photography I: the perception of food portion size from photographs. British Journal of Nutrition 1994; 72: 649-63.

21 Robinson F, Morritz W, McGuiness P, Hackett AF. A study of the use of a photographic food atlas to estimate served and self-served portion sizes. Journal of Human Nutrition and Dietetics 1997; 10: 117-24.

22 Robson PJ, Livingstone MB. An evaluation of food photographs as a tool for quantifying food and nutrient intakes. Public Health Nutrition 2000; 3: 183-92. 